\title{
As orações relativas no falar feirense: uma descrição preliminar
}

\author{
The relative clauses in Feirense speech: A preliminary description \\ Jéssica Carneiro da Silva* \\ Universidade Estadual de Feira de Santana, Feira de Santana, Bahia, Brasil \\ Cristina Figueiredo** \\ Universidade Federal da Bahia, Salvador, Bahia, Brasil \\ Silvana Silva de Farias Araújo*** \\ Universidade Estadual de Feira de Santana, Feira de Santana, Bahia, Brasil
}

\begin{abstract}
Resumo: Neste trabalho, faz-se uma discussão teórica e uma revisão de literatura sobre as estratégias de relativização, traçando explicações acerca das cinco estratégias existentes: 1. A relativa padrão; 2. A relativa padrão com lembrete; 3 . A relativa pied piping; 4. A relativa cortadora; 5 . A relativa cortadora com lembrete, descrevendo suas funções sintáticas. Revisitam-se os pressupostos teóricos da Sociolinguística Laboviana, discutindo os principais conceitos, ideias e perspectivas, correlacionando-os com um breve percurso sócio-histórico sobre a cidade de Feira de Santana, situada no semiárido baiano, região também conhecida como a zona da agropecuária. Em linhas gerais, este trabalho reúne discussões sucintas sobre a sócio-história do português brasileiro $(\mathrm{PB})$ - levando em conta aspectos como o forte contato linguístico e a transmissão linguística irregular - e a sócio-história do município baiano de Feira de Santana -, enfatizando suas características comerciais, o fator migratório e sua posição geográfica. Ademais, busca-se elencar uma variação de ordem sintática no português feirense falado, representada por dados reais de fala extraídos do projeto $A$ lingua portuguesa do semiárido baiano - Fase 3: amostras da lingua falada em Feira de Santana-Ba, sediado no Núcleo de Estudos da Língua Portuguesa (NELP), descrevendo-se os possíveis fatores linguísticos e sociais dessa variação, com a finalidade de difundir os resultados parciais obtidos na pesquisa desenvolvida no âmbito do Programa de Pós-Graduação em Estudos Linguísticos da Universidade Estadual de Feira de Santana (UEFS), com a dissertação de mestrado intitulada "As orações relativas no português falado em Feira de Santana", em andamento.
\end{abstract}

Palavras-chave: Sociolinguística. Sócio-história do PB. Oraç̃es Relativas. Português feirense.

\begin{abstract}
This paper is a theoretical discussion and a literature review on the relativization strategies by tracing a brief explanation of the existing three strategies: 1 . The relative standard; 2 . The relative standard with resumptive; 3 . The relative pied piping; 4 . The relative cutter; 5 . The relative cutter with resumptive, describing its syntactic functions. It revisits the theoretical assumptions of Sociolinguistics Labovian, discussing the main concepts, ideas and perspectives correlating with a brief socio-historical background of the city Feira de Santana, located in Bahia's semi-arid region also known as an agricultural area. In general, this work brings together discussions on the socio-history of Brazilian Portuguese (BP) - taking into account aspects such as strong language contact and irregular linguistic transmission - and the social history of the Bahian city of Feira de Santana - emphasizing their commercial characteristics, the migration factor and its geographical position. In addition, we seek to list a syntactical order variation in the spoken Feirense Portuguese, represented by actual speech data extracted from the project The Portuguese of Bahia semi-arid - Phase 3: samples of spoken language in Feira de Santana, Bahia, based on the group studies of Portuguese Language (NELP), describing the possible linguistic and social factors of this variation, in order to spread partial results and substantiate the research of the dissertation entitled "The relative clauses in the spoken Portuguese in Feira de Santana."
\end{abstract}

Keywords: Sociolinguistics. Social history of PB. Relative Clauses. Feirense Portuguese.

\footnotetext{
* Universidade Estadual de Feira de Santana, bolsista CAPES/UEFS, mestranda do Programa de Pós-Graduação em Estudos Linguísticos (PPGEL). E-mail: jessxcs@gmail.com.

**Professora Adjunta do Instituto de Letras da Universidade Federal da Bahia. E-mail: macrisfig@uol.com.br.

***Professora da Universidade Estadual de Feira de Santana, coordenadora do Mestrado em Estudos Linguísticos (MEL) do Departamento de Letras e Artes da UEFS. E-mail: silvana.uefs.2014@gmail.com.
} 


\section{INTRODUÇÃO}

Os estudos sobre a linguagem tomam um novo rumo quando, na década de 1960, William Labov conduz pesquisas de campo que investigavam a língua em seu uso real de fala e, assim, abre um caminho inovador para a dimensão sócio-histórica do fenômeno linguístico, considerando a variação no funcionamento da língua e nos processos de mudança linguística, sem deixar de lado a sua dimensão social. Para desconstruir a ideia da homogeneidade linguística, que já não mais atendia às necessidades científicas da época, Weinreich, Herzog e Labov (1968) sintetizam suas ideias na obra "Fundamentos empíricos para uma teoria da mudança linguística", texto base de todo e qualquer estudo sociolinguístico.

A perspectiva da heterogeneidade linguística e a concepção de que as línguas estão em constante variação e mudança impulsionaram diversos trabalhos científicos que discutiram e divulgaram a diversidade linguística. Quanto ao português brasileiro (PB), essa diversidade pode ser observada do campo da variação diastrática ao campo da variação diafásica; do campo lexical ao campo sintático. Trabalhos sobre a realidade linguística do português falado no Brasil revelaram um comportamento variável em diversos fenômenos sintáticos, tais como: na concordância entre os elementos do sintagma nominal, na concordância entre o sujeito e o verbo, na realização do sujeito pronominal e do objeto anafórico, na escolha das estratégias de relativização, entre outros. Esses trabalhos comprovam que o português falado no Brasil é uma língua pluralizada, heterogênea, variável e, segundo Lucchesi (1994, 2001, 2015), polarizada. De acordo com o autor, a realidade linguística brasileira apresenta duas normas distintas, a norma culta e a popular, uma situação que se justifica pela realidade sóciohistórica brasileira, principalmente, do período de colonização.

Embora a variação no PB seja significativamente atestada em diversas pesquisas, as gramáticas normativas ainda não registram a realidade linguística que se encontra no falar dos brasileiros.

Neste trabalho, estuda-se a variação das estratégias de relativização em amostras de fala popular do município de Feira de Santana, localizado no estado da Bahia. Esse fenômeno variável já foi investigado em outros estudos, a exemplos dos realizados por Tarallo (1983), Bispo (2009), Burgos (2003), Ribeiro (2009), Ribeiro e Figueiredo (2009), que consideraram outras comunidades de fala. Dentre as estratégias de relativização observadas no PB, além das relativas consideradas padrão, como em (1), encontram-se pelo menos duas não registradas nas gramáticas normativas, portanto consideradas não padrão: são as relativas com pronome lembrete, como em (2a) e as relativas cortadoras, como em (2b).

a. O doce que comprei na padaria ontem estava muito gostoso.

b. Esse é o vestido com que saí ontem.

a. O doce que comprei o/ele na padaria ontem estava muito gostoso.

b. Esse é o vestido Ø que sai ontem.

Este estudo foi desenvolvido no âmbito da Sociolinguística Variacionista, conforme Labov $(1966$; 1972) e buscou descrever as possibilidades de relativização no português feirense, demonstrando que é na sua diversidade que se encontram as riquezas linguísticas e culturais do povo brasileiro.

Além da análise dos fenômenos linguísticos de acordo com a Sociolinguística Variacionista, faz-se necessário destacar a formação sócio-histórica do município de Feira de Santana-BA, bem como a do PB, que remete a um período colonial, caracterizado pelo intenso contato linguístico e cultural, unindo falares indígenas, portugueses e africanos. Logo, 
é fundamental considerar a história social da comunidade de fala, como recomenda Labov (1966; 1972).

Sobre a formação histórica e social do município de Feira de Santana, encontram-se registros de que essa não era uma região povoada por escravos afrodescentes, mas por sujeitos vindos da zona rural com a finalidade de comercialização de seus produtos. Segundo Almeida (2012), Feira, como é carinhosamente chamada pelos seus atuais residentes, foi constituída pela migração de "nortistas" advindos de regiões do norte e do nordeste do Brasil, em um misto de dialetos e aspectos culturais. Dessa forma, o município caracteriza-se por ter uma comunidade de fala singular, com a qual é possível destacar o entrecruzamento do contato rural com o urbano, já que esse município agrega falares de diversas localidades da Bahia e do Brasil.

Têm-se como objetivos descrever as estratégias de relativização e, compreender o comportamento variável desse fenômeno no português falado em Feira de Santana. Além disso, pretende-se elencar fatos da sócio-história do brasileira e do municio de Feira de Santana, a fim de provocar uma reflexão sobre a variação nas estratégias de relativização.

Este artigo está assim organizado: na seção 2, faz-se uma apresentação do tema, descrevendo as principais estratégias de relativização encontradas no $\mathrm{PB}$, além de ser feita uma breve revisão da literatura; na seção 3, tecem-se considerações sobre os pressupostos teórico-metodológicos adotados nesta pesquisa, contextualizando, inclusive, o surgimento da Sociolinguística Variacionista e enfatizando a importância da contextualização sóciohistórica nas pesquisas sociolinguísticas; na seção 4, são apresentados os principais resultados obtidos na análise variacionista e, por fim, na seção 5, são apresentadas as considerações finais, sendo expostas as principais conclusões a que se chegou com este estudo.

\section{AS ESTRATÉGIAS DE RELATIVIZAÇÃO}

As orações relativas, denominadas pela tradição gramatical (LIMA, 1984; BECHARA, 1985; NEVES, 2000) de orações subordinadas adjetivas, modificam um nome dando origem a um constituinte complexo ${ }^{1 *}$ que integra a oração principal ou matriz. No exemplo em (3), a seguir:

Os móveis que comprei chegam amanhã.

a oração subordinada destacada modifica o núcleo nominal móveis, restringindo-o. E o constituinte complexo formado exerce a função de sujeito na oração principal ou matriz, cujo núcleo predicador é chegam. Essa construção chama-se relativa por ser introduzida por um pronome relativo (que no exemplo em (3)), cujas funções são: i) introduzir a oração encaixada, estabelecendo coesão sequencial entre duas orações, e ii) retomar o nome que o antecede, estabelecendo coesão referencial ${ }^{* *}$. Além disso, o pronome relativo exerce função sintática na oração de que faz parte. Em (03), o relativo que exerce a função sintática de objeto direto, conforme evidencia a divisão da sentença em duas orações em (4):

Os móveis chegam amanhã. / Eu comprei [os móveis] oD.

A lacuna na posição de objeto direto do verbo comprar em (3) visa demonstrar que o objeto direto foi deslocado de sua posição de origem para a posição inicial da oração

\footnotetext{
*Sintagma constituído por um núcleo nominal modificado ou complementado por uma oração subordinada.

${ }^{* *}$ As orações relativas podem ocorrer sem antecedente. Elas são chamadas de relativas livres ou relativas sem cabeça. Neste trabalho, não se tratou desse tipo de relativa. Será focalizado em trabalhos posteriores.
} 
encaixada, devido à necessidade de retomar o núcleo nominal da oração matriz e estabelecer a coesão entre as orações. Quando o pronome relativo exerce funções sintáticas que requerem preposição, o pronome relativo deve também ser precedido de preposição, deixando uma lacuna na posição de origem do sintagma preposicional relativizado, como no exemplo em (5). A esse tipo de relativas, Tarallo (1993) denominou de relativa pied piping.

Todos compraram o livro a que referi durante a palestra.

Tendo em vista a lacuna na posição de origem do sintagma relativizado, as orações relativas consideradas padrão, principalmente em trabalhos de cunho gerativistas (TARALLO, 1993, RIBEIRO, 2009; RIBEIRO; FIGUEIREDO, 2009), são chamadas de relativas com lacuna.

As orações relativas, segundo a tradição gramatical, são introduzidas pelos pronomes relativos elencados em (6).

a. variáveis: o qual, cujo

b. invariáveis: que, quem, onde, quanto e como

Os relativos, como dito anteriormente, exercem função sintática na oração principal: funções não preposicionadas, sujeito e objeto direto, e funções preposicionadas, objeto indireto, complemento oblíquo, adjunto adverbial, agente da passiva.

Sobre as relativas é também interessante registrar que elas modificam o núcleo nominal, restringindo-o ou especificando-o, como em (7), ou acrescentando uma informação a mais ao termo a que se refere, como em (8).

A professora está procurando o menino que fugiu da sala de aula ontem.

A professora está procurando o Pedrinho, que fugiu da sala de aula ontem.

(RIBEIRO; FIGUEIREDO, 2009)

Em (7), a oração subordinada, destacada em itálico, restringe o sentido do termo menino, que semanticamente é [-específico]. Dessa forma, a oração relativa é essencial à referencialidade desse nome. Esse tipo de oração é denominado de relativa restritiva. Em (8), a oração subordinada em destaque detalha e amplia as informações sobre o núcleo nominal a que se refere, Pedrinho, visto que é semanticamente [+específico]. Portanto, a oração relativa é desnecessária à identificação desse nome. Chama-se de relativa explicativa a oração subordinada que tem essa função.

Análises do PB demonstram que as estratégias indicadas como padrão pela tradição gramatical variam com estruturas consideradas não padrão. Tarallo (1983, 1993), que realiza uma pesquisa de cunho diacrônico sobre as estratégias de relativização, diagnostica que, no $\mathrm{PB}$, há três estratégias de relativização: i) relativa padrão ou relativa com lacuna, como nos exemplos em (3) e em (5); ii) relativa com pronome lembrete, ou com a lacuna preenchida, como no exemplo em (9); e iii) relativa cortadora, como no exemplo em (10).

(09) Esse é o rapaz [que encontrei ele no restaurante com sua mãe].

Em (9), de acordo com a tradição gramatical, o pronome relativo que retoma o núcleo nominal rapaz e exerce a função de objeto direto na oração subordinada. Porém, na posição de objeto direto, verifica-se a presença do pronome pessoal ele, que, por retomar mais uma vez o núcleo nominal da sentença matriz, é considerado um pronome lembrete ou resumptivo. Pronomes lembretes também ocorrem em relativas pied piping. As estratégias 
sem lacuna são consideradas não padrão pela tradição gramatical e, de acordo com Tarallo (1983), são estigmatizadas socialmente.

O terceiro tipo de relativas encontrado no $\mathrm{PB}$, a relativa cortadora, varia particularmente com as relativas pied piping e consiste na não realização da preposição diante do pronome relativo, como se vê no exemplo em (10), a seguir.

Todos compraram o livro que referi durante a palestra.

Na sentença em (10), o termo relativizado é um complemento oblíquo que requer uma preposição, referi-me ao livro, portanto a preposição, de acordo com o que prescreve a tradição gramatical, deveria preceder o relativo que. Embora considerada não padrão, essa estratégia não é estigmatizada e, por esse motivo, no $\mathrm{PB}$, vem se tornado mais frequente que a variante padrão em que a preposição é realizada (TARALLO, 1993, BURGOS, 2003, RIBEIRO 2009).

Os resultados dos estudos diacrônicos de Tarallo (1993, p. 88) revelaram, considerando as sincronias $(1725,1775,1825,1880)$, a ascensão da variante cortadora com o passar do tempo $(0,9 \%, 4,0 \%, 7,5 \%, 59,5 \%)$, e a queda das relativas pied piping $(89,2 \%, 88,1 \%, 91,3 \%$, $35,4 \%$ ), apontando para um processo de mudança, ou seja, de substituição da estratégia padrão pela estratégia não padrão. Quanto às relativas com pronome lembrete, no corpus analisado pelo autor, mantêm um comportamento equilibrado, exceto na terceira sincronia $(9,9 \%, 7,9 \%, 1,3 \%, 5,1 \%)$ e apresentam um comportamento marginal no sistema sintático do PB.

Os resultados de Tarallo (1993) quanto à variação entre a estratégia com lacuna e a com pronome lembrete nas estruturas de relativização de sujeito e de objeto direto, funções que não requerem preposição, apontam para a predominância das estratégias com lacuna em detrimento da estratégia com pronome lembrete. Quando sujeito é relativizado, verificam-se $89,7 \%$ de relativas com lacuna e, quando é o objeto direto relativizado, 97,4\%.

Bispo (2009) analisou as estratégias de relativização em dois corpora de amostras de fala. A primeira amostra reuniu um total de 36 informantes do D\&G Rio de Janeiro perfazendo 782 ocorrências de relativas, das quais $662(84,7 \%)$ eram do tipo padrão incluindo as relativas preposicionadas, $14(1,8 \%)$ relativas lembretes e $106(13,5 \%)$ representavam as cortadoras em contraponto á $03(0,7 \%)$ ocorrências de relativa pied piping. A segunda amostra, um corpus constituído na cidade de Natal, é quantitativamente mais significativa que a primeira. O autor computou 1621 estruturas com relativas, das quais 1384 (85,4\%) eram de relativa padrão. No que diz respeito à variação nas estruturas relativas que requerem uma preposição, das 252 ocorrências encontradas, as cortadoras totalizam 210 (83\%) ocorrências, enquanto as relativas pied piping representam (17\%), 42 ocorrências. Esses resultados corroboram os obtidos por Tarallo $(1983,1993)$, que revelam a ascensão das cortadoras no PB no último período analisado pelo autor, 1880.

Burgos (2003) também realizou uma pesquisa empírica sobre realização variável das estratégias de uso das relativas não padrão no português rural afro-brasileiro, considerando que o contato entre línguas ocorrido durante o período de colonização no Brasil teria interferido na aquisição do português. Seu corpus se constituiu de amostras de fala da comunidade Helvécia, localizada no município de Nova Viçosa, estado da Bahia. Os dados de Burgos (2003) totalizaram 569 orações relativas. Chama atenção o fato de o autor não ter encontrado nenhuma ocorrência relativa pied piping e apenas 18 relativas com pronome lembrete. Em seu corpus, o autor computou 185 ocorrências de relativa cortadora.

Ribeiro (2009) também analisa as estratégias de relativização no dialeto rural afrobrasileiro do estado da Bahia, buscando explicar entre outros fatos o estatuto do que introdutor das sentenças relativas, considerando o contato do português com as línguas africanas. Seria um pronome relativo ou um complementador, como os que introduzem as 
orações substantivas e, portanto, não exerceria a função sintática na oração subordinada, estabelecendo apenas a coesão sequencial entre as orações? Essa discussão já havia sido realizada por Tarallo (1983) para o PB e por Brito (1991) para português europeu (PE). De acordo com Brito (1991, apud RIBEIRO, 2009), o que nas construções de relativas de sujeito e de objeto direto seria um complementador e a lacuna existente na sentença encaixada seria interpretada como uma categoria vazia*. Seria um pronome relativo nas construções em que são relativizadas as funções preposicionadas, relativas pied piping, e estabeleceria a coesão sequencial e referencial entre as duas sentenças, além de exercer função sintática na oração subordinada.

Observando o comportamento dos complementadores e dos pronomes relativos em diversas línguas naturais e comparando com o comportamento do que nas comunidades rurais afro-brasileiras, Ribeiro propõe que, devido ao processo de transmissão linguística irregular como consequência do contato do português com as línguas africanas, esse morfema teria passado por um processo de mudança em relação ao português europeu. Para os contextos em que Brito (1991) propõe que esse morfema tem o status de pronome relativo para o PE, Ribeiro (2009) afirma que, no dialeto do português rural afro-brasileiro, esse morfema é um complementador.

Ribeiro e Figueiredo (2009) analisam o português escrito no século XIX por africanos alforriados a fim de verificar se, no processo de aquisição de segunda língua, ocorre um comportamento semelhante ao observado no PB, presença das estratégias com pronome lembrete e da cortadora. Porém, os resultados demonstraram que o português desses africanos reflete a gramática portuguesa. Dentre as 17 ocorrências de relativa em funções preposicionadas encontradas no corpus, verificou-se apenas 01 de relativa cortadora. Salientase que o período em que foram escritos os documentos analisados pelas autoras coincide com o período em que Tarallo (1993) registra a implementação desse tipo de estratégia. Portanto, os resultados obtidos pelas autoras vão de encontro aos apresentados por Tarallo (1993).

Na seção seguinte, está detalhado o quadro teórico-metodológico, incluindo a teoria e os métodos utilizados para a obtenção dos resultados.

\section{QUADRO TEÓRICO-METODOLÓGICO}

\subsection{Sociolinguística e sócio-história do português brasileiro}

Sistematizada por Labov, Weinreich e Herzog (1968), a Teoria da Variação e da Mudança Linguística identifica a impossibilidade de perceber a mudança linguística fora da comunidade de fala. Para essa teoria, a mudança deve ser compreendida dentro da vida social da comunidade de fala em que ela é produzida, pois a língua sofre pressões e influências sociais constantemente. Os teóricos citados afirmaram que a mudança não é proveniente de uma deriva aleatória devida à variação inerente na comunidade de fala.

Além de contextualizar a mudança linguística, a Teoria da Variação infere que, para analisar a variação e/ou mudança linguística, é fundamental considerar explicações linguísticas e extralinguísticas. Ou seja, é preciso que se investiguem os fatores que condicionam a escolha do falante pelas variantes em competição, a partir da observação dos padrões coletivos de comportamentos linguísticos numa dada comunidade de fala, a qual é interpelada por fatores linguísticos e sociais.

\footnotetext{
*Sobre as categorias vazias ver MIOTO C.; SILVA, M. C. F.; LOPES, R. E. V. Novo manual de sintaxe. Florianópolis: Insular, 2004.
} 
No início do século XX, antes da ascensão de uma teoria que abarcasse a variação e a mudança linguística, Meillet (1926) propôs que toda modificação na estrutura social acarreta uma mudança nas condições nas quais a linguagem se desenvolve, logo, a constituição das línguas está intimamente atrelada à história da cultura e da sociedade. Dessa forma, o estudo de qualquer fenômeno linguístico deve considerar o contexto sócio-histórico da comunidade de fala. No caso deste trabalho, o contexto sócio-histórico em que se formou o PB se inscreve como um aspecto fundamental para se compreender o português falado em Feira de Santana, bem como o do município de Feira de Santana.

No que concerne a sócio-história do PB, Araújo (2009, p.116) afirma que "o expressivo contato da língua portuguesa com os falantes de línguas africanas que adquiriram o português em situações precárias, bem como a aquisição da língua portuguesa pelos imigrantes europeus e asiáticos marcaram a história sociolinguística brasileira". Tais fatos reforçam a compreensão de que os contatos linguísticos que ocorreram na época colonial foram importantes para a formação da realidade linguística brasileira e para a constituição da língua que é majoritariamente falada no Brasil.

Sobre a sócio-história do município de Feira de Santana-BA, entende-se que o processo migratório, a sua localização geográfica e seu poderio comercial resultaram em um intenso contato linguístico de dialetos advindos de migrantes do interior da Bahia e de outros estados que se deslocaram para Feira, com a finalidade de troca comercial. Segundo Almeida, (2012, s.p.) "[...] as origens da sede do município de Feira de Santana remontam ao século XVIII e a um passado eminentemente rural, caracterizando-se por ser um lugar de pouso para viajantes, vaqueiros e suas boiadas, que vinham de toda a microrregião e até de outros estados".

De acordo com Araújo (2014, p.157), o município se urbanizou devido a uma forte atração comercial, advinda de uma feira de gado e da venda de produtos e continua a atrair pessoas de diversas localidades devido o seu rico comércio e indústrias. A autora afirma que

Feira de Santana abrigou uma importante feira de gado, atraindo pessoas de diversas regiões para a compra de gado e de produtos no período colonial, também, no período republicano, continuou a atrair pessoas, mas, principalmente pelo seu rico comércio, consolidando-se como 'um empório do sertão', denominação atribuída comumente por jornalistas da época (ARAUJO, 2014, p.157).

Inicialmente, o contato linguístico em Feira de Santana ocorreu entre portugueses de diferentes localidades, paulistas, crioulos, descendentes de índios, e, atualmente, ocorre entre os dialetos nordestinos e, em menor escala, com outros dialetos, segundo Almeida (2012). Por essas características peculiares, o município circunscreve-se como uma comunidade de fala singular, com a qual é possível destacar o entrecruzamento do contato rural com o urbano, já que este município agrega falares de diversas localidades da Bahia e do Brasil.

Por possuir esse entrecruzamento do contato rural com o urbano na sua formação sócio-histórica, pode-se observar que, em Feira de Santana, há um intenso contato entre as normas popular e culta do português brasileiro, permitindo assim apoiar as ideias de Mattos e Silva (2014) de que há uma provável aproximação das normas popular e culta do PB, ou seja, tais normas podem estar em processo de aproximação com influências mútuas, já que, a partir do século XX, ocorreram mudanças profundas e contínuas no Brasil, inferência proposta por Lucchesi (2001). Isto é, a ideia de multilinguismo localizado atrelada à constituição histórica e social dessa região baiana fornece subsídios para a característica multiadialetal do PB. 


\subsection{A amostra investigada}

As amostras de fala analisadas pertencem ao acervo do Projeto A lingua portuguesa do semiárido baiano - Fase 3: amostras da lingua falada em Feira de Santana-Ba, sediado no Núcleo de Estudos da Língua Portuguesa (NELP) ${ }^{2}$, do Departamento de Letras e Artes da Universidade Estadual de Feira de Santana. Os inquéritos foram gravados de 2007 a 2011 e os informantes foram selecionados de acordo com as variáveis sociais registradas no Quadro 1, a seguir. (ARAUJO; ALMEIDA, 2014, p. 35):

Quadro 1: Fatores socioculturais utilizados na constituição da amostra do Projeto de Pesquisa A língua Portuguesa no Semiárido Baiano - Fase 3

\begin{tabular}{|l|l|}
\hline \multicolumn{2}{|c|}{ FATORES SOCIOCULTURAIS } \\
\hline \multirow{2}{*}{ Gênero } & Masculino \\
\cline { 2 - 2 } & Feminino \\
\hline \multirow{3}{*}{ Faixa etária } & Faixa I (25-35 anos) \\
\cline { 2 - 2 } & Faixa II (45-55 anos) \\
\cline { 2 - 2 } $\begin{array}{l}\text { Relação com a } \\
\text { migração }\end{array}$ & Faixa III (acima de 65 anos) \\
\hline \multirow{3}{*}{ Escolaridade } & Feirenses filhos de feirenses \\
\cline { 2 - 2 } & Feirenses filhos de migrantes \\
\cline { 2 - 2 } & Baixantes ou inexistente - (semi)analfabetos \\
\cline { 2 - 2 } & Ensino Médio completo \\
\cline { 2 - 2 } & Ensino superior completo e/ou pós graduação \\
\hline
\end{tabular}

Para a realização desse estudo preliminar* sobre as estratégias de relativização apresentado neste artigo, foram analisadas amostras de fala de 04 inquéritos do corpus do português popular ${ }^{* *}$ de Feira de Santana-BA, distribuídos em duas faixas estarias: faixa I e faixa III.

Após o levantamento dos dados, com base em fatores sociais destacados anteriormente e os fatores linguísticos resultaram em duas variáveis, a variável dependente 1 : relativa padrão versus relativa padrão com lembrete; e a variável dependente 2: relativa piedpiping, relativa cortadora versus relativa cortadora com lembrete.

As variáveis independentes consideradas para a essa análise foram a função sintática do relativo, a função sintática do antecedente e o pronome relativo. Posteriormente, ao passo que a pesquisa for avançando, mais variáveis serão analisadas e inseridas na chave de codificação. Finalizada a codificação, os dados foram quantificados pelo programa computacional Goldvarb X (2005).

A próxima seção consiste na apresentação da análise quantitativa e qualitativa dos resultados encontrados após as rodadas.

\section{ANÁLISE DOS RESULTADOS}

Os resultados parciais apresentados nesta seção fazem parte de uma pesquisa em andamento que investigará as estratégias de relativização em 24 inquéritos, buscando descrever e comparar a norma culta com a norma popular do português falado em Feira de Santana-BA. Descrevem-se neste artigo amostras de fala da norma popular de apenas 04 informantes feirenses de baixa escolaridade, distribuídos em 02 faixas etárias: Faixa I e Faixa

\footnotetext{
2 Núcleo de Estudos da Língua Portuguesa (NELP), disponível em: < http://www2.uefs.br/nelp/projetos.htm>.

*Esse estudo é parte da pesquisa da dissertação de mestrado intitulada "As orações relativas no português falado em Feira de Santana" em andamento, por SILVA, J. C. da; ARAÚJO, S. S. de F.; FIGUEIREDO, C.

${ }^{* *}$ Utiliza-se o conceito da bipolarização de normas do português brasileiro, com base em Lucchesi (1994, 2001, 2015, entre outros).
} 
III. Nesse estudo piloto, a análise quantitativa dos dados revelou um total de 176 dados de estruturas de relativização com antecedente. A análise das estratégias de relativização requer que, na quantificação dos dados, sejam propostas duas variáveis dependentes, conforme a seguir:

Variável dependente 1 - Diz respeito à relativização de funções que não requerem preposição ou que o relativo dispense a preposição (onde e cujo), como no exemplo em (11). As variantes que constituem essa variável dependente são: a relativa padrão ou com lacuna, como em (12), e a relativa não preposicionada com lembrete, como em (13).

(13) Hoje em dia eu tenho uma irmã [que ela tem o segundo grau].

Considerando a variável dependente 1, foram registradas 131 ocorrências, todas de relativas com lacuna. A ausência de relativas não preposicionadas com lembrete parece apontar para o fato de essa estratégia ainda receber uma avaliação social negativa, como propôs Tarallo (1993). Nesses contextos, observaram-se 128 retomadas pelo relativo que, com função de sujeito e objeto direto, como nos exemplos em (14) e apenas 03 pelo relativo onde com função locativa, como nos exemplos em (15).

(14) a. Sujeito:

Que segurança tem? Tem uma aviaturinha [que passa lá]. [INF01.P.CA.F1.M]

b. Objeto direto:

Os mestre de obra [que tem aqui dento] vem com sua equipe pronta. [INF01.P.CA.F1.M]

(15) a. A escola era ali [onde hoje é a biblioteca]. [INF09P.I.F3.M]

b. Aí chegava na praça ali... João Pedreira... subia na Praça João Pedreira, passava pela praça da Bandeira [onde tem aqueles abrigo]. [INF09P.I.F3.M]

c. Nunca estudei em Colégio. Professora? A primeira professora era branquinha, era jovem, era daqui de Feira e ensinava em São Vicente, num fazenda lá, [onde a gente morava]. [INF10P.FC.F3.F]

$V$ ariável dependente 2 - Diz respeito à variação que ocorre entre as estratégias que relativizam uma função preposicionada e que, segundo a tradição gramatical, a preposição deve preceder o relativo. São as variantes: a relativa pied piping, como em (15), a relativa cortadora, como em (16) e a relativa cortadora com lembrete (17).

(16) Carlos é um menino [de que todos gostam__ $]$ ].

(17) Carlos é um menino [que todos gostam __ ].

(18) Carlos é um menino [que todos gostam dele].

Quanto aos dados referentes às funções preposicionadas, foram computadas 45 ocorrências, sendo 43 de relativa cortadora, como no exemplo em (18), 02 pied piping, como em (19) e 02 cortadoras com lembrete, como em (20). Esses resultados são bastante interessantes se comparados com os do grupo da variável dependente 1 . As variantes com 
lacuna predominam nos dois grupos, porém, no primeiro grupo, predomina a estratégia padrão, enquanto no segundo grupo, a estratégia não padrão, ou seja, as cortadoras.

(19) Tem o dia das mães [Ø que (= para o qual) o coral tá ensaiando]. [INF12.P.C.F3.F]

(20) a. A pessoa esquece por alguns aquele momento em que ele tá alcoolizado. [INF02.P.J.F1.M]

b._Minha mãe se mudou e aí o lugar [pra onde ela foi] não tinha escola perto e ai parei. [INF10.P.FC.F3.F]

(21) a. Tem um vizinho meu que foi um assaltado, mataram por causa do dinheiro, o dinheiro [que ele vei em casa atrás dele]. [INF01.P.I.F1.F]

b. Eu tenho um filho [ $\varnothing$ que gosto muito desse filho]. [INF10.P.FC.F3.F]

No exemplo em (20b), não se verifica uma retomada por pronome lembrete, mas por um sintagma preposicionado que retoma o antecedente do relativo. Considerou-se uma estratégia com lembrete pelo fato de a posição de origem do relativo estar preenchida.

O resultado do uso das estratégias de relativização das funções preposicionadas pode ser visto na Tabela 1 , a seguir.

Tabela 1 - Distribuição das estratégias de relativização das funções preposicionadas

\begin{tabular}{l|c|c}
\hline Fatores & Ocorrências & Percentual \\
\hline Relativa pied piping & 2 & $2 \%$ \\
\hline Relativa cortadora & 43 & $\mathbf{9 6 \%}$ \\
\hline $\begin{array}{l}\text { Relativa cortadora com } \\
\text { pronome lembrete }\end{array}$ & 2 & $2 \%$ \\
\hline Total & 45 & $100 \%$ \\
\hline
\end{tabular}

Os números registrados na Tabela 1 corroboram a hipótese de Tarallo (1983) de que houve uma mudança no campo sintático do português brasileiro. Segundo o autor, a partir da segunda metade do século XIX, ocorreu a ascensão da relativa cortadora e um acentuado desuso da relativa pied piping. A predominância da estratégia cortadora sobre a pied piping também é verificada nos estudos de Burgos (2003), Bispo (2009), Ribeiro (2009), como visto na seção 2.

Embora as gramáticas apresentem um elenco diverso de pronomes relativos, no corpus do português popular de Feira de Santana, ocorreram apenas os relativos que, onde.

Tabela 2 - Tipos de relativos encontrados

\begin{tabular}{c|c|r}
\hline QUE & ONDE & \multirow{2}{*}{ Total } \\
\hline Ocor. $/ \%$ & Ocor. $/ \%$ & 176 \\
\hline $172 / 98$ & $4 / 2$ & 176 \\
\hline
\end{tabular}

Observou-se o uso generalizado do relativo que (172 das 176 ocorrências) substituindo os demais relativos. No corpus, esse relativo foi encontrado substituindo: cujo, que tem função genitiva/de posse, como em (22), quando, expressando tempo, como em (23), quanto, expressando quantidade, como em (24), onde, expressando lugar, como em (25), quem, como em (26), e o qual, como em (19). Esse uso generalizado de que corrobora a análise de Ribeiro 
(2009) no que diz respeito ao fato de esse morfema, no PB, ter o status de complementador, em todas as estruturas de relativização, conforme discutido na seção 2, uma mudança ocorrida no português se levado em consideração o que propôs Brito (1991) para o PE.

(22) Eu sei que ouço contar assim que ela começou nos Olhos d’Água, com dona Ana e o marido que não sei o nome. [INF10.P.FC.F3.F] $q u e=$ cujo nome eu não sei.

(23) Eá noite que tem o jornal que a gente pega um pouquinho. [INF02.P.L.F1.F] que $=$ quando tem o jornal.

(24) Todas as opções de tudo que tem de bebida, tem todas as opções de música, várias opções no palco, não para. [INF01.P.CA.F1.M] que $=$ De tudo quanto tem.

(25) Tem ruas aqui que o esgoto é em céu aberto, na rua que a minha tia mora o esgoto é em céu aberto. [INF02.P.L.F1.F] $q u e=\mathrm{Na}$ rua onde minha tia mora.

(26) Eu tenho um filho que gosto muito desse filho. [INF10.P.FC.F3.F] que $=$ Eu tenho um filho de quem eu gosto muito desse filho.

Foi controlada a função sintática do pronome relativo, a fim de verificar se as funções condicionam a escolha das estratégias de relativização, porém os resultados, como se vê na próxima tabela, não revelam variação significativa.

Tabela 3 - Atuação da função sintática do relativo nas estratégias de relativização do falar feirense.

\begin{tabular}{l|c|c|c|c|c}
\hline $\begin{array}{l}\text { Função } \\
\text { sintática do } \\
\text { relativo }\end{array}$ & Padrão & Piedpiping & Cortadora & $\begin{array}{c}\text { Cort. com } \\
\text { lembrete }\end{array}$ & \multirow{2}{*}{ Total } \\
\cline { 2 - 5 } & Ocor./\% & Ocor./\% & Ocor./\% & Ocor. $/ \%$ & \\
\hline Sujeito & $85 / 100$ & - & - & - & 85 \\
\hline Objeto direto & $42 / 100$ & - & - & - & 42 \\
\hline Objeto oblíquo & $1 / 2$ & - & $13 / 86$ & $1 / 2$ & 15 \\
\hline Comp. Locativo & $1 / 7$ & $2 / 7$ & $5 / 79$ & $1 / 7$ & 9 \\
\hline Adj. adverbial & $2 / 8$ & - & $24 / 92$ & - & 26 \\
\hline Total & $131 / 74$ & $2 / 1$ & $43 / 24$ & $2 / 1$ & 176 \\
\hline
\end{tabular}

Vê-se, na Tabela 3, que as posições sintáticas mais relativizadas são as de sujeito e de objeto direto, como em (13). Esse resultado também foi observado no português rural afrobrasileiro (BURGOS, 2003, RIBEIRO, 2009). Não está computada, na tabela, 01 ocorrência de que com função de genitivo, como em (21).

Os números da tabela revelam que, no corpus analisado, a estratégia cortadora é mais frequente quando a função de adjunto adverbial é relativizada, 24 das 43 ocorrências e menos frequente quando relativizado um complemento locativo.

Exemplos das demais funções do relativo podem ser vistos nos exemplos a seguir. É apresentado um exemplo de cada tipo de relativa, seguindo a ordem da tabela. 
(27) Objeto oblíquo:
a. Nunca estudei em Colégio. Professora? A primeira professora era branquinha, era jovem, era daqui de Feira e ensinava em São Vicente, num fazenda lá, [onde a gente morava]. [INF10.P.FC.F3.F]
b. Esse ano é ano de eleição, até agora meu voto também ninguém vai ter, fiz uma promessa que eu não voto mais em ninguém, depois desse governador [que eu votei], não gostei , joguei meu voto fora. [INF02 L. F1. F]
c. Eu tenho um filho [Ø que gosto muito desse filho]. [INF10.P.FC.F3.F]

(28) Complemento locativo:

a. Nunca estudei em Colégio. Professora? A primeira professora era branquinha, era jovem, era daqui de Feira e ensinava em São Vicente, num fazenda lá, [onde a gente morava]. [INF10.P.FC.F3.F]

b. Minha mãe se mudou e aí o lugar [pra onde ela foi] não tinha escola perto e ai parei. [INF10.P.FC.F3.F]

c. Teu irmão no bairro [Ø que eu moro não pisa não]. [INF01P.CA.F1.M]

d. A única casa [que eu entro nela] é a de L. Mas não sou muito chegada a casa do vizinho não. [INF10P.F.C.F3.F]

(29) Adjunto adverbial:

a. Aí chegava na praça ali... João Pedreira... subia na Praça João Pedreira, passava pela praça da Bandeira [onde tem aqueles abrigo]. [INF09P.I.F3.M]

b. Não o menino da mobilete que mataram com um tiro de piostola, ali naquela área [que J. trabaia]. [INF01P.CA.F1.M]

Outro grupo de fator relevante para a construção das orações relativas é o da função sintática do antecedente. A tabela a seguir revela os contextos em o antecedente ocorre.

Tabela 4 - Atuação da função sintática do antecedente nas estratégias de relativização do falar feirense.

\begin{tabular}{l|c}
\hline $\begin{array}{l}\text { Função sintática do } \\
\text { antecedente }\end{array}$ & Ocor. $/ \%$ \\
\hline Compl. verbal & $60 / 34$ \\
\hline Sujeito & $37 / 21$ \\
\hline Adj. adverbial & $31 / 18,5$ \\
\hline Predicativo & $17 / 10$ \\
\hline Aposto & $14 / 8$ \\
\hline Tópico & $11 / 6$ \\
\hline Comp. Nominal & $5 / 3$ \\
\hline Genitivo & $1 / 0,5$ \\
\hline Total & $176 / 100 \%$ \\
\hline
\end{tabular}

Como se vê na tabela acima, o encaixamento das relativas se dá, principalmente, nas posições argumentais, sendo mais frequente na posição de complemento verbal, com 34\%, seguido pelo encaixamento na posição de sujeito, 21\%. Esses resultados refletem os obtidos por Ribeiro e Figueiredo (2009) em pesquisa sobre o português falado por africanos do 
século XIX, em que afirmam, com base em trabalhos de aquisição de L1 e L2, ser essa uma tendência das línguas naturais. É também bastante frequente, no português feirense, o encaixamento das relativas em sintagmas adverbiais, portanto posição final. Como se verificam as posições mais encaixadas na sentença, complemento nominal e adjunto nominal, desfavorecem o encaixamento das relativas, com 05 e 01 ocorrências, respectivamente.

Das variáveis sociais controladas, faixa etária e sexo, revelou-se interessante para a compreensão do uso da estratégia cortadora no português popular feirense apenas a variável faixa etária do informante, subdividida em Faixa I e Faixa III. A quantificação dos dados de acordo com essa variável tem-se os seguintes resultados:

Tabela 5 - Atuação da variável Faixa Etária no uso da relativa cortadora na fala popular de Feira de Santana-BA.

\begin{tabular}{l|c|c|c|c|c}
\hline \multirow{2}{*}{ Fatores } & $\begin{array}{c}\text { Relativa } \\
\text { Padrão }\end{array}$ & $\begin{array}{c}\text { Relativa } \\
\text { pied piping }\end{array}$ & $\begin{array}{c}\text { Relativa } \\
\text { cortadora }\end{array}$ & $\begin{array}{c}\text { Cort. com } \\
\text { lembrete }\end{array}$ & \multirow{2}{*}{ Ocor. $\%$} \\
\cline { 2 - 5 } Faixa I & $96 / 74$ & $1 / 1$ & $33 / 25$ & - & 130 \\
\hline Faixa III & $35 / 76$ & $1 / 2$ & $8 / 22$ & 2 & 46 \\
\hline TOTAL & $131 / 74$ & $2 / 1$ & $43 / 24$ & $2 / 1$ & 176 \\
\hline
\end{tabular}

Observa-se que os informantes mais jovens empregam a estratégia cortadora e a padrão com uma frequência mais elevada que os falantes mais idosos. A ausência de variação significativa entre as estratégias de relativização não favoreceu a realização de uma análise interpretativa em relação à atuação da variável faixa etária no uso das estratégias de relativização, tampouco foi possível fazer projeções em termos de mudança linguística.

\section{CONSIDERAÇÕES FINAIS}

Com este breve estudo sobre as estratégias de relativização do português feirense, buscou-se fomentar questões sociolinguísticas sobre a variação e a mudança linguística no $\mathrm{PB}$, considerando a interferência da sócio-história do PB na constituição do falar feirense.

Foram computadas no corpus 176 ocorrências de relativas com antecedente, sendo a maior parte (131) de relativas padrão não preposicionadas, seguidas pelas relativas cortadoras (43) e, de maneira pouco significativa, pela relativa com pronome lembrete (02) pela relativa pied piping (02).

Embora se tenha realizado uma análise parcial do falar feirense, os resultados obtidos apontam para fatos bastante interessantes. Esses resultados são elencados a seguir:

a. O uso quase exclusivo do relativo que nas estratégias de relativização;

b. Ausência de variação entre as relativas com lembrete e as com lacuna não preposicionadas;

c. Predominância das relativas cortadoras em detrimento das relativas pied piping;

d. Predominância da relativização das funções de sujeito e de objeto direto;

e. Preferência pelo encaixamento nas posições de complemento verbal, sujeito e adjunto adverbial.

Os resultados permitiram ratificar a ideia de que o português brasileiro distanciou-se do português europeu, gerando características próprias, peculiares de um país pluralizado, 
diversificado, tanto na sua constituição sociocultural quanto na língua que é falada nos quatro cantos do território brasileiro.

\section{REFERÊNCIAS}

ALMEIDA, L. F. de. Urbanização, escolarização e variação linguística em Feira de SantanaBahia (século XX). Tabuleiro de Letras: Revista do Programa de Pós-Graduação em Estudo de Linguagens, Universidade do Estado da Bahia - UNEB, Departamento de Ciências Humanas - DCH I, n. 04, jun. 2012.

ARAUJO, S. S. de F. A concordância verbal no português falado em Feira de Santana: sociolinguística e sócio-história do português brasileiro. 2014, 342f. Tese (Doutorado em Linguística) Instituto de Letras, Universidade Federal da Bahia, Salvador, 2014.

ALMEIDA, N. L. F. de. O projeto A língua portuguesa no semiárido baiano - Fase 3: critérios de constituição e da amostragem do Banco de dados. In: FREITAG, R. M. Ko. (Org.). Metodologia de coleta e manipulação de dados em Sociolinguística. São Paulo: Edgard Blücher, 2014, p. 27-47.

ARAUjO, J. M. de O.A Formação sócio-histórica do português do Brasil: contribuições do recôncavo baiano. Cadernos de Letras da UFF: Dossiê Difusão da língua portuguesa, Niterói: n. 39, p. 95-116, 2009. Disponível em: < http://www.cadernosdeletras.uff.br/joomla/images/stories/edicoes/39/artigo5.pdf>. Acesso em: 27 maio 2016.

BAGNO, M. Português ou brasileiro? Um convite à pesquisa. 2. ed. São Paulo: Parabólica, 2001.

BISPO, E. B. Estratégias de relativização no português brasileiro e implicações para o ensino: o caso das cortadoras. 2009, 162 f. Dissertação (Mestrado em Linguística). Universidade Federal do Rio Grande do Norte, Natal, 2009.

BECHARA, E. Lições de português pela análise sintática. 13. ed. Rio de Janeiro: Padrão, 1985.

BURGOS, E. Estratégias de Uso das Relativas em uma comunidade de fala afro-brasileira. 2003, $122 \mathrm{f}$. Dissertação (Mestrado em Letras e Linguística) - Instituto de Letras, Universidade Federal da Bahia, Salvador, 2003.

CUNHA, Celso Ferreira. Gramática da língua portuguesa. 11. ed. 2. Rio de Janeiro: FAE, 1986.

LABOV, W. Sociolinguistics patterns. 3. ed. Philadelphia: University of Pensylvania Press, 1972.

LUCCHESI, D. Variação e norma: elementos para uma caracterização sociolingüística do português do Brasil. Revista Internacional de Lingua Portuguesa, Lisboa: Associação das Universidades de Língua Portuguesa, n.12, 1994. p. 17-28.

D. As duas grandes vertentes da história sociolingüística do Brasil (1500-2000), Revista D.E.L.T.A., São Paulo: v.17, n.1, p. 97-132, 2001. Disponível em: <http://www.scielo.br/pdf/delta/v17n1/a05v17n1.pdf>. Acesso em: 19 jun 2016. 
Lingua e sociedade partidas: a polarização sociolinguística do Brasil. São Paulo: Contexto, 2015.

LUCCHESI, D. ARAÚJO, S. S. de F. A Teoria da variação linguística. s.d.(Texto em homepage do Projeto Vertentes) Disponível em: <bttp://mmw.vertentes.ufba.br/a-teoria-da-variacaolinguistica>. Acesso em 28 maio 2016.

MATTOS E SILVA, R. V. Ensaios para uma sócio-história do português brasileiro. São Paulo: Parábola Editorial, 2004.

MIOTO C.; SILVA, M. C. F.; LOPES, R. E. V. Novo manual de sintaxe. Florianópolis: Insular, 2004.

NEVES, M. H. de M. Gramática de usos do português. São Paulo: UNESP, 2000.

RIBEIRO, I. As sentenças relativas. In: LUCCHESI, D. (Org.). O português afro-brasileiro. Salvador: EDUFBA, 2009. p. 185-208.ROCHA LIMA, Carlos Henrique. Gramática normativa da lingua portuguesa. 24. ed. Rio de Janeiro: José Olympio, 1984.

RIBEIRO, Ilza; FIGUEIREDO, Cristina. Relativas. In: LOBO, Tânia;

RIBEIRO, Ilza; FIGUEIREDO, Cristina. Relativas. In: OLIVEIRA, Klebson. Africa à Vista: Dez estudos sobre o português escrito por africanos no Brasil do século XIX. Salvador: EDUFBA, 2009. p. 208-240.

TARALLO, Fernando. Diagnosticando uma gramática Brasileira: o português d'aquém e d'além-mar ao final do século XIX. In: ROBERTS, Ian; KATO, Mary (orgs). Português Brasileiro: uma viagem diacrônica. 2. ed. Campinas: Editora da UNICAMP, 1993 (versão original em inglês 1991). p. 69-100.

TARALLO, F. L. Relativization strategies in brą̧ilian portuguese. (Estratégias de relativização no português brasileiro). 1983. 273 f. Tese (Doutorado em Linguística), Pensilvânia: Universidade da Pensilvânia, 1983.

WEINREICH, U. LABOV, W. HERZOG, M. Fundamentos empíricos para uma teoria da mudança linguística. Tradução de Marcos Bagno; revisão técnica de Carlos Alberto Faraco; posfácio de Maria da Conceição Paiva e Maria Eugênia L. Duarte. São Paulo: Parábola, 2006. 